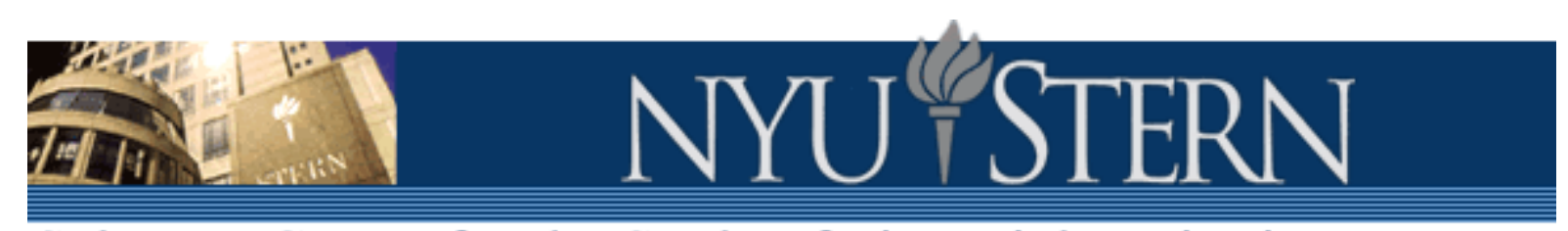

Salomon Center for the Study of Financial Institutions

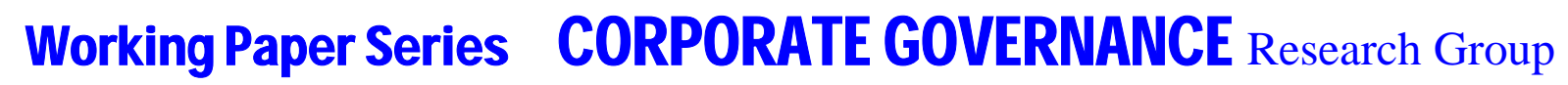

CORPORATE GOVERNANCE OVER THE BUSINESS CYCLE

Thomas Philippon

S-CG-03-03 


\title{
Corporate Governance over the Business Cycle *
}

\author{
Thomas Philippon ${ }^{\dagger}$ \\ NYU-Stern
}

July 2003

\begin{abstract}
I provide empirical evidence that badly governed firms respond more to aggregate shocks than do well governed firms. I build a simple model where managers are prone to overinvest and where shareholders are more willing to tolerate such a behavior in good times. The model successfully explains the average profit differences as well as the cyclical behavior of sales, employment and investment for firms with different governance qualities. The quantitative results suggest that governance conflicts can explain $30 \%$ of aggregate volatility.
\end{abstract}

\footnotetext{
${ }^{*}$ I am grateful to Olivier Blanchard and Ricardo Caballero for invaluable discussions. I have also benefited from the comments of Manuel Amador, Mark Gertler and Ivan Werning. I thank Daron Acemoglu, David Bowman, John Faust, Francesco Franco, Augustin Landier, Gordon Phillips, John Reuter, Roberto Rigobon, Bernard Salanie and Michael Woodford, as well as seminar participants at the NBER summer institute, the Federal Reserve Board, the IMF, MIT, Harvard, NYU, Wharton, Delta and CREST for their comments.

${ }^{\dagger}$ Contact: New York University, Stern School of Business, Department of Finance, Suite 9-190, 44 West 4th Street, New York, NY 10012.
} 


\section{Introduction}

I propose a simple model to study the implications of corporate governance for the business cycle, based on the idea that managers tend to expand their firms beyond the profitmaximizing size. What matters for aggregate volatility is whether these deviations from profit maximization are more likely to happen in booms or in recessions. This, in turn, depends on how the relative costs and benefits of monitoring firms' decisions change with the state of the economy. I take the view that the comparative advantage of managers is to come up with new ideas to seize profit opportunities, and that scrutinizing managerial decisions is a time consuming process. Since it is particularly costly to miss a profit opportunity when the demand for the firm's product is high, shareholders are more willing to leave discretionary authority in the hands of managers in good times than in bad times.

I study the implications of these governance conflicts in a standard dynamic macro model with imperfect competition in the goods markets. Imperfect competition is important because it creates rents over which managers and shareholders can fight. Managerial tendencies to increase investment, employment and output - together with the proposition that shareholders leave more discretion to managers in good times - implies that corporate governance conflicts amplify aggregate fluctuations. Quantitative simulations, based on the new empirical evidence presented in section 2, suggest that aggregate volatility would be $30 \%$ lower if all firms were always perfectly governed.

This research is related to the microeconomic literature on governance conflicts between managers and shareholders. Jensen (1986) emphasizes the idea that managers tend to expand their firms beyond the profit-maximizing size. On the macroeconomic side, I build on Blanchard and Kiyotaki (1987) and on Rotemberg and Woodford (1992) ${ }^{1}$ for the role of imperfect competition, and on Bernanke, Gertler, and Gilchrist (1999) for the implications of financial frictions.

Section 2 provides new evidence on the business cycle properties of firms with different governance qualities. Section 3 and 4 present the model. Section 5 explains the intuition for the amplification mechanism. Section 6 discusses the calibration method and how it

\footnotetext{
${ }^{1}$ The empirical finding that markups of prices over marginal costs are counter-cyclical is relevant for my paper because a firm operating on its demand curve can expand its output only by lowering its markup. See Rotemberg and Woodford (1999) for a survey, and Bils and Kahn (2000) for recent evidence.
} 
relates to the existing empirical literature about governance conflicts. Section 7 presents the impulse responses and the simulations of the model. Section 8 concludes. Derivations and technical details are in the appendix.

\section{Evidence}

Figure 1 shows that firms with bad governance have lower profit margins. The governance data come from the Investor Responsibility Research Center and are based on 24 distinct corporate-governance provisions. Gompers, Ishii, and Metrick (2003) construct an index by adding one for every provision that reduces shareholders rights, so that higher values mean worse governance. The index is constructed for the 1990's. The profit margin is the ratio of median income during the period 1989-2001 to median capital expenditures during the same period, relative to the average of firms in the same industry and age group. The figure shows that the profit to investment ratio of badly governed firms is $6 \%$ below average, while the profit to investment ration of well governed firms is $7 \%$ above average. The difference is significant at the $5 \%$ level. These results are in line with Gompers, Ishii, and Metrick (2003) who report that badly governed firms have lower profits to sales ratios.

The original index ranges from 5 to 14 , and I have created three groups with cutoffs at 8 and 12 , corresponding to the 25 th and 75 th percentiles of the distribution of the index. I will use these three groups in the calibration exercise. The governance index is not available for all years and all firms, and it can vary over time. To be on the safe side, I decided to compare firms with persistently bad governance to firms with persistently good governance, and I kept only the firms whose index has a standard deviation of less than one over the sample period. In practice, the index is very persistent over time and the results are robust to keeping all firms. I sort firms among the three groups according to the earliest available index.

Figures $2 \mathrm{a}$ and $2 \mathrm{~b}$ show that the capital expenditures and sales of firms with bad governance are more cyclical than the investment and sales of firms with good governance. Sensitivity to aggregate shocks is defined as the regression coefficient, $\beta$, of the growth rate of capital expenditures (sales) on the growth rate of aggregate private non-residential 
investment (GDP):

$$
g_{i t}=\alpha_{i}+\left(\beta_{\text {Governance }}+\gamma_{\text {Industry }}+\delta_{\text {Age }}\right) \times \bar{g}_{t}+\varepsilon_{i t}
$$

Industry is the one digit SIC code of firm $i$. Age is the age group, using 5 groups and cutoffs at percentiles $(10,25,50,75)$. Equivalently, I could have computed the betas by running a separate time series regression for each firm, and adjusting later for age and industry effects ${ }^{2}$. The regression results are reported in table 1. Figure 2 is based on regressions 4 and 8 . On average, when aggregate investment increases by $1 \%$, the capital expenditures increase by $1.35 \%$ for firms with bad governance, and by $0.65 \%$ for firms with good governance: The difference is 0.7 as reported in table 1, column 4. Quite remarkably, the same is true for sales growth and for employment growth: Along all margins, badly governed firms expand more in booms, and contract more in recessions than do well governed firms.

\section{Model}

I introduce governance issues into a standard general equilibrium model. The consumers solve

$$
\max _{K_{t+1}, L_{t}, C_{t}, u_{t}} E_{0}\left[\sum_{t} \beta^{t}\left(\log \left(C_{t}\right)-\frac{1}{Z_{t}} \frac{\phi}{\phi+1} L_{t}^{\frac{\phi+1}{\phi}}\right)\right]
$$

subject to the budget constraint

$$
(1+g) K_{t+1}=\left(1-\delta\left(u_{t}\right)\right) K_{t}+W_{t} L_{t}+u_{t} R_{t} K_{t}+\Pi_{t}-C_{t}-\frac{\gamma}{2} \frac{\left(K_{t+1}-K_{t}\right)^{2}}{K_{t}}
$$

$R_{t}$ is the rental price of capital services, $u_{t}$ is the rate of utilization of the existing stock of capital $K_{t}, \Pi_{t}$ are aggregate profits, $g$ is the trend growth rate of labor productivity and $\gamma$ captures adjustment costs for investment. $Z_{t}$ is an exogenous aggregate labor supply shock $^{3}$. The cost of higher utilization is captured by an increase in the depreciation rate $\delta\left(u_{t}\right)$ as in King and Rebelo (1999). Capital utilization is introduced only because it is important in the quantitative analysis. It plays no role for the theory.

\footnotetext{
${ }^{2}$ This gives the same results. The results would be numerically identical if there were no missing values (i.e. perfectly balanced panel). In selecting the sample, I have allowed no more than 1 missing year per firm. The number of missing values is slightly larger for capital expenditures, as can be seen at the bottom of table 1 .

${ }^{3}$ Labor supply shocks provide a convenient way to introduce aggregate shocks that do not directly affect the technological frontier of the economy. They can be interpreted, for instance, as nominal spending shocks that interact with nominal wage rigidities. See Chari, Kehoe, and McGrattan (2002)
} 
The economy produces a final good using differentiated inputs. The final good is produced competitively and it can be used for consumption and investment. The differentiated goods are produced by a continuum of mass $N$ of firms indexed from 0 to 1 . $N$ will be determined in equilibrium by a free entry condition. The production function for the final $\operatorname{good}$ is $^{4}$

$$
Y_{t}=N \times\left(\int_{0}^{1} y_{i t}^{\frac{\sigma-1}{\sigma}}\right)^{\frac{\sigma}{\sigma-1}}
$$

and the final good producers solve

$$
\max _{y_{i t}} P_{t} Y_{t}-N \times \int_{0}^{1} p_{i t} y_{i t}
$$

where $y_{i t}$ is the production of intermediate good $i$ at time $t$.

Equation (3) implies that each intermediate producer $i$ faces an isoelastic demand curve:

$$
y_{i t}=\frac{Y_{t}}{N} \times\left(\frac{p_{i t}}{P_{t}}\right)^{-\sigma}
$$

The price level, $P_{t}$, is such that $\int_{0}^{1}\left(\frac{p_{i t}}{P_{t}}\right)^{1-\sigma}=1$. This is also the zero profit condition for the final good producers. There is monopolistic competition in the differentiated goods sector. The production function for intermediate good $i$ is characterized by constant returns to variable factors and some fixed costs. The variable factors are the flows of capital and labor services: $k_{i t}$ and $l_{i t}$. Note that $k_{i t}$ includes utilization ${ }^{5}$. The production function for $\operatorname{good} i$ at time $t$ is:

$$
y_{i t}=\theta_{t} q_{i t} k_{i t}^{1-\alpha} l_{i t}^{\alpha}
$$

$\theta_{t}$ is an exogenous aggregate technology $\operatorname{shock}^{6}$ and $q_{i t}$ is the endogenous firm-specific productivity (to be discussed shortly). The fixed costs for firm $i$ are $\Phi_{i t}$ units of final good.

\footnotetext{
${ }^{4}$ I choose the measure of firms to be uniform and I omit $d i$ when it is obvious that the integration refers to $i$.

${ }^{5}$ It makes the notations simpler ( $u_{t}$ appears only in the aggregate resource constraint below) and, since capital can be freely traded between firms, it is inconsequential. For the same reason, the assumption that the utilization rate is chosen by the capital holders (consumers) is also inconsequential.

${ }^{6} \mathrm{I}$ do not vary $Z$ and $\theta$ at the same time. I calibrate using either one or the other. I introduce $\theta$ for the sake of completeness. Since I have verified that the quantitative and qualitative results do not depend on whether the economy is driven by $\theta$ or by $Z$, I report only the simulations with $Z$. The one exception concerns the behavior of the real wage. For that variable, the value added of the model with governance is higher if one considers shocks that do not change the aggregate technology, such as demand shocks (remember that demand shocks together with nominal wage inertia are equivalent to shocks to $Z$ ). Demand shocks without governance conflicts imply a counter-cyclical real wage, as discussed in section 7 . The governance model overturns this counter-factual prediction - as would any model of counter-cyclical markups.
} 
The (real) profits of firm $i$ are therefore:

$$
\pi_{i t}=\frac{p_{i t}}{P_{t}} y_{i t}-W_{t} l_{i t}-R_{t} k_{i t}-\Phi_{i t}
$$

I now describe the governance environment. To make the problem non-trivial, I assume that managers have a comparative advantage in running the firms, but that their objectives differ from the ones of the shareholders. When managers run the firms, the productivity is $q_{i t}=1$. Let $\left\{k^{m}, l^{m}, \Phi\right\}$ be the profit maximizing solution: The fixed cost $\Phi$ is exogenously given by technology, and $\left\{k^{m}, l^{m}\right\}$ maximize (6) subject to (4) and (5) with $q_{i t}=1$. However, governance conflicts are such that managers do not always implement the profit maximizing solution. Specifically, I assume that managers' favorite implementation is $\left\{\left(1+\eta^{*}\right) k^{m},\left(1+\eta^{*}\right) l^{m},\left(1+\tau^{*}\right) \Phi\right\}$. In words, managers prefer firms that are larger by $\eta^{*}$ for capital and labor, and by $\tau^{*}$ for fixed costs. This is consistent with much of the corporate finance literature: I will discuss the existing evidence when I calibrate the model. I introduce two parameters (and only two) for both theoretical and empirical reasons. Theoretically, $\eta^{*}$ and $\tau^{*}$ mean different things: $\eta^{*}$ rises output while $\tau^{*}$ does not. Empirically, $\eta^{*}$ will capture the idea that managers prefer to buy the latest machines even if they are not really needed, or that they over-estimate the appropriate scale of operation for their firms (for instance because they over-estimate their own productivity $q$ ). On the other hand, $\tau^{*}$ will capture the standard managerial perks (private jets,...) as well as outright stealing and excessive compensation. Finally, the evidence presented in section 2 suggests that one parameter $\left(\eta^{*}\right)$ is enough to capture the behavior of sales, investment and employment.

Shareholders have a monitoring technology that allows them to enforce profit maximization, but with a lower productivity, $\underline{q}_{i} \leq 1$, which is distributed across firms according to the c.d.f. $F(q)$. I will use $\underline{q}_{i}$ as the measure of governance quality for firm $i$ : When $\underline{q}_{i}=1$, shareholders can enforce their rights without cost. When $\underline{q}_{i}<1$, it is costly to control the manager. The decision to use the "managerial" technology $\left\{1 ; \eta^{*} ; \tau^{*}\right\}$ or the alternative technology $\left\{\underline{q}_{i} ; 0 ; 0\right\}$ is made to maximize the value of the firm ${ }^{7}$.

A rational expectations equilibrium for this economy is a set of stochastic processes for the exogenous shocks (either $\theta_{t}$ or $Z_{t}$ ) and for the endogenous prices and quantities. $\left\{l_{i t}, k_{i t}, p_{i t}\right\}_{i}$ solve the intermediate firms' program described above, $\left\{Y_{t}, y_{i t}\right\}$ are deter-

\footnotetext{
${ }^{7}$ The appendix contains a discussion of the role of financial incentives.
} 
mined by (3), and consumers maximize (1) over $\left\{K_{t+1}, C_{t}, L_{t}, u_{t},\right\}^{8}$. All the agents take $\left\{P_{t}, W_{t}, R_{t}\right\}$ as given, and the following market clearing conditions hold:

$$
\begin{aligned}
Y_{t} & =C_{t}+I_{t}+N \times \int_{0}^{1} \Phi_{i t} \\
u_{t} K_{t} & =N \times \int_{0}^{1} k_{i t} \\
L_{t} & =N \times \int_{0}^{1} l_{i t}
\end{aligned}
$$

This definition of equilibrium is conditional on the number of firms, $N$, which is constant at business cycle frequencies. To pin down $N$, I impose that a free entry condition holds in the non-stochastic steady state of the economy (see Rotemberg and Woodford (1999) and the appendix).

\section{Corporate Governance}

One can think of the governance technology in the following way. Agents inside the firm (CEO, managers, employees) come up with plans to take advantage of profit opportunities as they appear. A plan specifies a technology and the amounts of capital and labor that must be hired to implement it. Supervisors (the board for the CEO, the CEO for the division managers) can either rubber-stamp the plan proposed by the agent, or they can scrutinize it. Scrutinizing is time consuming and entails the possibility that the profit opportunity will be missed, so that the expected productivity under close monitoring drops to $\underline{q}_{i}$. On the other hand, scrutinizing allows the supervisors to cut wasteful expenses $\left(\tau^{*}\right.$ : inefficiencies, private jets, outright stealing..), and to make sure that the project is implemented on the right scale $\left(\eta^{*}\right.$ : buying expensive machines, hiring too many employees, refusing to close down a plant..).

Proposition 1 describes the optimal choice to rubber-stamp or to monitor closely for firm $i$ at time $t$.

Proposition 1 The shareholders of firm $i$ rubber-stamp managerial propositions if and only if

$$
q_{i}<Q_{t}
$$

\footnotetext{
${ }^{8}$ The assumption that consumers choose $u_{t}$ is immaterial as long as there are no firm specific adjustment costs.
} 
where

$$
Q_{t}=\left(\kappa\left(\eta^{*}\right)-\frac{\tau^{*} \Phi}{A_{t}}\right)^{\frac{1}{\sigma-1}}
$$

and

$$
\begin{aligned}
A_{t} & \equiv\left(\frac{\mu}{\theta_{t}}\left(\frac{R_{t}}{1-\alpha}\right)^{1-\alpha}\left(\frac{W_{t}}{\alpha}\right)^{\alpha}\right)^{1-\sigma} \frac{Y_{t}}{\sigma N} \\
\kappa\left(\eta^{*}\right) & \equiv\left(1+\eta^{*}\right) \times \frac{\mu\left(1+\eta^{*}\right)^{-\frac{1}{\sigma}}-1}{\mu-1} ; \mu=\frac{\sigma}{\sigma-1}
\end{aligned}
$$

Proof. The decision rule is simple: the shareholders will rubber-stamp if and only if

$$
\pi_{t}^{m}(\underline{q})<\pi^{*}(1)
$$

Using some simple algebra, one can see that the maximum profits are

$$
\pi_{t}^{m}(q)=A_{t} q^{\sigma-1}-\Phi
$$

And the profits from the manager's favorite choice are

$$
\pi_{t}^{*}(1)=A_{t} \kappa^{*}-\left(1+\tau^{*}\right) \Phi
$$

So the optimal choice is to rubber-stamp if and only if:

$$
A_{t} q^{\sigma-1}<A_{t} \kappa^{*}-\tau^{*} \Phi
$$

QED.

Proposition 1 says that governance decisions are characterized by a simple cutoff rule: strict profit maximization is enforced in all firms with governance quality above $Q_{t}$, while managerial decisions are rubber-stamped in all firms below the cutoff. The factor $A_{t}$ captures the influence of the state of the economy on the profits of the firms: higher output $Y_{t}$ means higher profits, and higher marginal cost $\frac{1}{\theta_{t}}\left(\frac{R_{t}}{1-\alpha}\right)^{1-\alpha}\left(\frac{W_{t}}{\alpha}\right)^{\alpha}$ means lower profits. The influence of the parameter $\tau^{*}$ is straightforward. The influence of $\eta^{*}$ is slightly more subtle: The profit losses are summarized by the function $\kappa\left(\eta^{*}\right)$, which is concave and reaches a maximum for $\eta^{*}=0$. Starting from the optimal size $\left(k^{m}, l^{m}\right)$, a small deviation by $\eta^{*}$ implies only a second order loss in profits. 
The measure of firms that rubber-stamp managerial propositions is $F\left(Q_{t}\right)$. The crucial point is that it is an increasing function of $A_{t}$. This result follows from the assumption that monitoring costs come from lower productivity: These costs are large when $A_{t}$ is large. On the other hand, the cost of rubber-stamping is less than proportional to $A$ because of the fixed component $\tau^{*}$. As a consequence, shareholders are more inclined to rubber-stamp managerial propositions in good times.

The profit margins of firms with bad governance are persistently lower than the ones of better governed firms. This fits figure 1. The model also implies that firms with different governance qualities have different cyclical properties: Firms with excellent governance always maximize profits, while firms with bad governance follow the objective function of their manager when $A_{t}$ is large and the objective function of the shareholders when $A_{t}$ is small. As a consequence, their capital spending increases and decreases more than proportionally with the business cycle. This fits figure $2^{9}$.

The next step is to investigate the quantitative implications of governance conflicts.

\section{Amplification}

Before turning to the simulations of the model, it is useful to present the intuition for the result that corporate governance amplifies aggregate fluctuations. From the definition of the aggregate price level and from the pricing decisions of the intermediate goods producers, one can obtain the following equation

$$
\mu \times \chi_{t}=\left[\left(1+\eta^{*}\right)^{\frac{1}{\mu}} \times F\left(Q_{t}\right)+G\left(Q_{t}\right)\right]^{\frac{1}{\sigma-1}}
$$

where

$$
\chi_{t} \equiv \frac{1}{\theta_{t}}\left(\frac{R_{t}}{1-\alpha}\right)^{1-\alpha}\left(\frac{W_{t}}{\alpha}\right)^{\alpha}
$$

is the marginal cost associated with the Cobb-Douglas production function. $F\left(Q_{t}\right)=$ $\int_{0}^{Q_{t}} f(q) d q$ and $G\left(Q_{t}\right)=\int_{Q_{t}}^{1} q^{\sigma-1} f(q) d q$. Equation (8) is shared by all general equilibrium models of imperfect competition where the pricing behavior of firms is described by $\frac{p_{i t}}{P_{t}}=$

\footnotetext{
${ }^{9}$ Note that the relationship can be non monotonic. In theory, a firm whose manager is totally entrenched will not react to aggregate shocks, simply because shareholders don't have a say. The question of whether such firms exist in the US is open, but the evidence in section 2 suggests that, in any event, such firms are rare. Of course, if one wants to apply this framework to other economies (emerging markets for instance), one would have to reconsider this question.
} 
$\mu_{i t} \times \chi_{i t}$. Most models focus on the symmetric equilibrium where all firms have the same marginal cost and the same markup. In a symmetric equilibrium, one would get the simple condition: $\mu \times \chi_{t}=1$. In my model however, firms differ in both their marginal costs and their markups. Firms that choose to delegate control have, on average, higher productivity and lower markups than other firms. Equation (8) can be seen either as defining the aggregate markup as a weighted average of the firms' markups or as defining the aggregate marginal cost as a weighted average of the firms' marginal costs. Because the markup choices are correlated with firms' idiosyncratic productivity, one cannot in general disentangle the aggregate markup from the aggregate marginal cost.

Consider equation (7), that defines the cutoff $Q_{t}$. In this equation, the RHS increases with $W_{t}$ and $R_{t}$ and decreases with $Y_{t}$. We can now understand the amplification mechanism. Consider the case of a positive shock. Following the shock, output and factor prices increase. If factor supplies are elastic, output will increase more than the real wage and rental price and this will push the cutoff $Q_{t}$ to the left. Some firms will then hire more capital and labor and increase their output. Again, if factor supplies are elastic, this will increase output more than $R_{t}$ and $W_{t}$, and $Q_{t}$ will move further to the left ${ }^{10}$. We therefore expect the amplification mechanism to be stronger when factor supplies are elastic. This is why the presence of capacity utilization is quantitatively important in this model. It is well understood that capacity utilization makes the standard RBC model more responsive to shocks. Here, this will also apply to the amplification factor over and above what the $\mathrm{RBC}$ would predict.

\section{Calibration}

The calibration exercise is conceptually straightforward. I take the standard technological parameters from the textbook, and I choose the parameters that describe the governance environment in order to match the results in Table 1 (columns 3 and 6, sample 1980-2001).

The steady state is computed to match the standard ratios $\left(\frac{C}{G D P}, \frac{W L}{G D P}, \frac{K}{G D P}\right)$. The labor supply elasticity is $\phi=4$ as in the benchmark RBC model. The elasticity of substitution

\footnotetext{
${ }^{10}$ This suggests that the model could have multiple equilibria. This is indeed a possibility. For the parameter values that I estimate however, firm level heterogeneity $\left(\underline{q}_{i}\right)$ is large enough to remove this possibility.
} 
between goods is $\sigma=4$, which implies a value-added markup of $33 \%$ as in Rotemberg and Woodford (1999). Recall that free entry drives the profits to 0 on the balanced growth path: This pins down $N$ as a function of $\Phi$ (normalized to 1) and $\sigma$. The adjustment cost parameter is $\gamma=4$ (at quarterly frequency), following Hall (2002). The elasticity of depreciation with respect to utilization is 0.1 as in King and Rebelo (1999), and the steady state utilization is normalized to $u=1$.

\begin{tabular}{|l|l|l|l|l|}
\hline$\mu$ & $\sigma$ & $\phi$ & $\gamma$ & $\frac{\delta^{\prime \prime}(1)}{\delta^{\prime}(1)}$ \\
\hline 1.33 & 4 & 4 & 4 & 0.1 \\
\hline
\end{tabular}

The governance environment is characterized by $\eta^{*}, \tau^{*}$ and the distribution $F(q)$. I assume that $q$ is distributed uniformly over $[\underline{q}, \bar{q}]$. I choose the four parameters $\left\{\eta^{*}, \tau^{*}, \underline{q}, \bar{q}\right\}$ to match the results in Table 1. This involves guessing initial values for the parameters, simulating a large number of firms and plotting the implied profit margins and investment betas for the quantiles of the governance distribution. The results are then compared to the ones in figure 2, and the exercise is repeated until they match. Note that the model must be solved at each iteration since aggregate and firm dynamics are jointly determined. The results are shown on figure $3 a, b$. The parameters are:

\begin{tabular}{|l|l|l|l|}
\hline$\tau^{*}$ & $\eta^{*}$ & $\underline{q}$ & $\bar{q}$ \\
\hline $22 \%$ & $20 \%$ & .91 & .99 \\
\hline
\end{tabular}

In steady state, the cutoff is such that $F(Q)=21 \%$.

Are these parameters consistent with what we know about corporate governance? Denis and Kruse (2000) show that corporate restructuring is triggered by declines in performance and that it involves major cost cutting efforts, plant closing, asset sales and layoffs. These restructuring efforts increase shareholder value (see also Gilson (1998)). Denis and Denis (1995) show that firms experience an average employment decline of 16 to $19 \%$ following a normal retirement of the CEO at age 65 , suggesting that firms are on average too fat ${ }^{11}$. Similarly, Kaplan (1989) finds that MBOs are followed by declines in employment, sales and investment, and by increases in profits. All this is consistent with my assumption about $\eta^{*}$ and $\tau^{*}$. More specifically for $\tau^{*}$, Berger and Ofek (1999) show that the amount of unallocated expenses is a strong determinant of corporate refocusing programs. They

\footnotetext{
${ }^{11}$ The figure rises to more than $40 \%$ after a forced resignation of the CEO. But this is of course an endogenous event, so this number cannot be taken at face value.
} 
also show that disciplinary events (shareholder pressure, financial distress, management turnover) usually occur before refocusing takes place and are followed by average cumulative abnormal returns of $7 \%$.

One can also obtain evidence from the literature that studies the effects of leverage on firms' behavior. Leverage has long been proposed as an efficient way to limit managerial discretion (Jensen (1986)). Empirically, one sees that more highly leveraged firms charge higher prices and respond more quickly and more strongly to shocks: Phillips (1995), Sharpe (1994), Chevalier and Scharfstein (1996). Kovenock and Phillips (1997) confirm the results in Kaplan (1989) that LBO firms decrease their investment and show that this effect is stronger in highly concentrated industries. The idea that leverage can be used to put pressure on insiders is also directly supported by the fact that boards increase the leverage of their companies in response to increases in unions' power (Gorton and Schmid (2000) for Germany, Bronars and Deere (1991) for the US). This prompted me to check whether leverage was relevant for my analysis: The results in table 1 do not change if one controls for leverage. Note, however, that my sample includes only large, publicly traded companies and that the results could be different for smaller firms.

\section{Impulse Responses and Simulations}

I log-linearize the model around its balanced growth path and I conduct two independent simulations, one for the labor shock $z_{t}=\log \left(Z_{t}\right)$ and one for the technology shock $\theta_{t}$. Except for real wages, the properties of the model do not depend on which shock is used, and I report only the results for the driving process $z_{t}$. All time series are detrended using the HP filter.

Figure 4 shows the response of the economy to a positive, persistent shock to $\log (Z)$. The shock is the dotted line. GDP is the solid line. The third line represents the fraction of firms whose CEOs enjoy some discretion. All the responses are in deviation from steady state. Following a shock of $1 \%$ to $\log (Z)$, GDP increases by $2.5 \%$ and the fraction of loosely controlled firms increases from $21 \%$ (steady state) to $22.3 \%$.

Figure 5 shows the amplification coming from the governance mechanism. In response to the same shock as in figure 4, the economy without governance conflict experiences a smaller 
increase in GDP. This shows the quantitative importance of the amplification mechanism described above.

In the simulations using historical data, the driving process (in logs) $z_{t}$ is specified as an $\operatorname{AR}(1)$ :

$$
z_{t}=\rho z_{t-1}+\varepsilon_{t}
$$

Note however that $z_{t}$ is not observable in the data and that $\rho$ is not known. The calibration procedure follows the strategy used by King and Rebelo (1999). I make an initial guess for $\rho$. Given this guess, I solve the model using rational expectations. The solution takes the form

$$
\hat{y}_{t}=\beta_{y k} \times \hat{k}_{t}+\beta_{y z} \times z_{t}
$$

The coefficient $\beta_{y k}$ and $\beta_{y z}$ are complex functions of all the parameters of the model and of $\rho$. This equation for output can be inverted into $z_{t}=\frac{1}{\beta_{y z}} \times \hat{y}_{t}-\frac{\beta_{y k}}{\beta_{y z}} \times \hat{k}_{t}$. Using actual values for $\hat{y}_{t}$ and $\hat{k}_{t}$, one can create a series for $z_{t}$. One can then compute the $\operatorname{AR}(1)$ coefficient for this series. It is, in general, different from the original $\rho$. This value is then used as a new starting point. The procedure is repeated until convergence. The estimated value of $\rho$ is .886 (I estimated essentially the same values of $\rho$ for $z$ and for $\theta$ ).

Figure 6 shows the simulated economy. The match in the top panel is mechanical: the shocks are chosen to fit the GDP series. The other 3 panels suggest that the model generates reasonable time series for the main macroeconomic variables. Figure 7 shows the time series of the fraction of firms that are loosely controlled. This fraction is higher in booms and lower in recession, thereby increasing aggregate volatility: For the same realizations of the exogenous shocks ( $z$ or $\theta$ ), the economy would have been $32.9 \%$ less volatile without governance conflicts. Figure 8 shows the historical Solow residual (defined in the standard way) and the simulated residual for the economy driven by the labor shock $z$. In this economy, short run fluctuations in the residual are due to the presence of fixed costs and variation in capacity utilization, not to aggregate technology shocks ${ }^{12}$. The simulated time series for the residual is close to its empirical counterpart, even though the model was not calibrated for that purpose. Among other things, this means that I could have chosen the shocks to fit the residuals, as in the RBC tradition (instead of the GDP series),

\footnotetext{
${ }^{12}$ The true technology is not exactly constant because $Q_{t}$ moves with the business cycle. The impact on the residual is small, however, as can be seen on the figure.
} 
and the model would have implied reasonable time series for GDP, consumption, hours and investment.

For the behavior of the real wage, the governance model generates a first order improvement over the alternative, in the case of business cycles driven by non-technological shocks. The model without endogenous governance and driven by $z_{t}$ predicts a counter-cyclical real wage: its correlation with the actual (HP-filtered) wage series is $-57 \%$. The governance model, on the other hand, delivers a correlation of $+52 \%$, because positive shocks induce firms to leave more discretion to insiders who are more willing to hire for a given real wage, and who are also more efficient at doing so. The aggregate labor demand therefore shifts out in good times, and this shift compensates the impact of decreasing returns to labor.

\section{Conclusion}

Consistent with the predictions of a simple model of firm governance, I have shown that badly governed firms have lower profit margins and are more cyclical than well governed firms. I have studied the mechanism through which governance conflicts amplify aggregate shocks. When times are good, insiders enjoy more control over the decisions of their firms, which leads to more hiring and more investment spending. These hiring and investment decisions feed-back into the aggregate and amplify the boom. The quantitative analysis suggests that corporate governance may be responsible for $30 \%$ of aggregate volatility.

While the goal of this paper was to provide a positive analysis of corporate governance over the business cycle, one can also use the framework to study normative questions. Several points are worth emphasizing. First, there is a close link between the normative and positive properties of the model: In booms, the labor demand shifts out since managers over-hire but profits must increase since this is what makes shareholders more willing to tolerate managerial misbehavior. Higher wages and higher profits mean that the amplification mechanism I have studied is a Pareto improvement. This is possible because shareholder value maximization is not the same as social value maximization when goods markets are not perfectly competitive. A second, related, point is that, from a macro-economic point of view, one should distinguish between different types of deviations from shareholder value, contrary to what the corporate finance literature usually does. In this paper, the key dis- 
tinction was between productive and unproductive deviations. Unproductive deviations (stealing, excessive compensation, inefficient organizational choices to preserve private interests) are bad for both society and shareholders. On the other hand, productive deviations (excessive $R \& D$ spending, reluctance to close down plants) create some social surplus as long as all markets are not perfectly competitive, and even though these deviations could become so large as to reduce social welfare, they should not be confused with the non productive deviations. It is perfectly possible for the economy to be closer to achieving aggregate efficiency exactly at the time where deviations from shareholder value are more common. Finally, a policy recommendation which is likely to be robust to the details of the model is that improving competition in the goods markets would bring the additional benefit of reducing the social costs of governance conflicts. 


\section{References}

Berger, P., And E. Ofek (1999): "Causes and Effects of Corporate Refocusing Programs," Review of Financial Studies, 12, 311-345.

Bernanke, B., M. Gertler, and S. Gilchrist (1999): "The financial accelerator in a quantitative business cycle framework," in Handbook of Macroeconomics, ed. by J. B. Taylor, and M. Woodford, vol. 1C. Elsevier Science, North Holland.

Bils, M., And J. Kahn (2000): "What Inventory Behavior Tells Us About Business Cycles," American Economic Review, 90, 458-480.

Blanchard, O. J., and N. Kiyotaki (1987): "Monopolistic Competition and the Effects of Aggregate Demand," American Economic Review, 77, 647-666.

Bronars, S., and D. Deere (1991): "The Threat of Unionization, the Use of Debt, and the Preservation of Shareholder Wealth," Quarterly Journal of Economics, 106, 231-254.

Chari, V. V., P. J. Kehoe, and E. R. McGrattan (2002): "Business Cycle Accounting," Working Paper 625, Federal Reserve Bank of Minneapolis.

Chevalier, J. A., And D. Scharfstein (1996): "Capital-market imperfections and countercyclical markups: Theory and evidence," American Economic Review, 86(4), 703-725.

Denis, D., And D. Denis (1995): "Performance Changes Following Top Management Dismissals," Journal of Finance, 50(4), 1029-1057.

Denis, D., And T. Kruse (2000): "Managerial discipline and corporate restructuring following performance declines," Journal of Financial Economics, 55(3), 391-424.

Gilson, S. (1998): "Creating Value through Corporate Restructuring," Working Paper, Harvard Business School.

Gompers, P., J. Ishit, And A. Metrick (2003): "Corporate Governance and Equity Prices," Quarterly Journal of Economics, pp. 107-155.

Gorton, G., And F. Schmid (2000): "Class struggle inside the firm: a study of German codetermination," NBER paper 7945. 
Hall, R. (2002): "Industry Dynamics with Adjustment Costs," Mimeo.

Jensen, M. (1986): "Agency Costs of Free Cash Flow, Corporate Finance and Takeovers," American Economic Review, 76(2), 323-329.

Kaplan, S. (1989): "The Effects of Management Buyouts on Operation and Value," Journal of Financial Economics, pp. 217-254.

King, R., And S. Rebelo (1999): "Resuscitating Real Business Cycles," in Handbook of Macroeconomics, ed. by J. B. Taylor, and M. Woodford, vol. 1B. Elsevier Science, North-Holland.

Kovenock, D., And G. Phillips (1997): "Capital Structure and Product Market Behavior: An Examination of Plant Exit and Investment Decisions," Review of Financial Studies, 10(3), 767-803.

Phillips, G. (1995): "Increased Debt and Industry Product Markets: An Empirical Analysis," Journal of Financial Economics, 37(2), 189-238.

Rotemberg, J., and M. Woodford (1992): "Oligopolistic Pricing and the Effects of Aggregate Demand on Economic Activity," Journal of Political Economy, 100(6), 11531207.

(1999): "The Cyclical Behavior of Prices and Costs," in Handbook of Macroeconomics, ed. by J. B. Taylor, and M. Woodford, vol. 1B. Elsevier Science, North Holland.

Sharpe, S. (1994): "Financial Imperfections, Firm Leverage and the Cyclicality of Employment," American Economic Review, 84(4), 1060-74. 


\section{A Evidence}

I start by matching the quarterly COMPUSTAT files with the data provided by Andrew Metrick on his web page. The governance index can potentially vary over time: I keep firms whose index has a standard deviation of less than one over the sample period (in practice the index is quite persistent). I keep only those firms that report non missing values for sales between 1989 and 2001. This leaves me with 626 firms. I take GDP, the non-residential private fixed investment and their deflators from the NIPA. I construct the annual growth rate of (deflated) capital expenditures of firm $i$ at time $t: g_{i t}=\log \left(\right.$ cape $\left._{i, t}\right)-$ $\log \left(\right.$ cape $\left._{i, t-1}\right)$. I winsorize this growth rate at $5-95 \%$ within each period to make sure that the results are not driven by outliers. I run the panel regression with fixed effects $\left(\alpha_{i}\right)$

$$
g_{i t}=\alpha_{i}+\beta\left(\text { age }_{i}, \text { industry }_{i}, \text { governance }_{i}\right) \times \bar{g}_{t}+\varepsilon_{i t}
$$

Industry is the one digit SIC code for firm $i$. Age is age group in the first year of the sample, using 5 groups and cutoffs at percentiles $(10,25,50,75)$. Equivalently, I have also computed the betas by running a time series regression for each firm, and adjusting later for age and industry effects. The results are the same.

\section{B Governance Model}

I now outline a simple moral hazard model and discuss the role of financial incentives. The main idea is the same as in the text: managers come up with new ideas that deliver productivity $q_{i t}=1$ but they do not share the objectives of the stockholders. The focus on CEO and shareholders is purely for convenience: The same model would apply to moral hazard problems inside the firm, between CEO and division managers for instance. There are 2 ways to implement the new technology and the manager chooses a probability distribution $(\tilde{e}, 1-\tilde{e})$ over the two implementations, and $\tilde{e}$ can take two values: $\tilde{e}=e$ or 1 . Each implementation delivers profits $\left(\pi_{t}\right)$ and private benefits $\left(B_{t}\right)$. Private benefits are not transferable and $\tilde{e}$ is not observable. I interpret the model as follows: managers can expand effort to cut all unnecessary expenses, fire all unnecessary employees, invest only the optimal amount of resources into new projects, etc.. These efforts are both costly for the manager and difficult to observe for the shareholders.

- Probability $\tilde{e}: \pi_{t}=A_{t}$ and $B_{t}=0$.

- Probability $1-\tilde{e}: \pi_{t}=A_{t} \kappa^{*}-\tau^{*} \Phi$ and $B_{t}=\tau^{*} \Phi+b A_{t}$.

$$
\text { Assumption A1: }(1-e)\left(1-\kappa^{*}\right)<b<1-\kappa^{*}
$$

The second inequality of Assumption 1 implies that the first best is to implement $\tilde{e}^{F B}=$ 1: if $\tilde{e}$ were contractible, all firms would choose $\tilde{e}^{F B}=1$ in every period. However, when $\tilde{e}$ is not contractible, the first inequality of $A 1$ implies that the second best (with general financial incentives and limited liability) is to implement $\tilde{e}^{S B}=e$.

In such a world, the possibility to intervene directly is obviously valuable: this is what the monitoring technology $\underline{q}_{i}$ does. A firm will choose the direct monitoring if and only if

$$
\underline{q}_{i}^{\sigma-1} A_{t}>e A_{t}+(1-e)\left(A_{t} \kappa^{*}-\tau^{*} \Phi\right)
$$


Note that I can always choose $b$ and $e$ such that $A 1$ holds and $e$ is close to 0 . In this case, the model boils down to the one used in the text. The cutoff is given by:

$$
Q_{t}=\left(\kappa^{*}-\frac{\tau^{*} \Phi}{A_{t}}\right)^{\frac{1}{\sigma-1}}
$$

\section{Technical Details}

The setup takes into account both capacity utilization $(u)$ and adjustment costs $(\gamma)$. I use $\vec{C}$ to denote the fact that $C$ has a trend (to be removed as soon as all the FOCs are derived). Consumers maximize:

$$
\max _{L_{t}, C_{t}} \sum_{t} \beta^{t}\left(\log \left(\vec{C}_{t}\right)-\frac{1}{Z_{t}} \frac{\phi}{\phi+1} L_{t}^{\frac{\phi+1}{\phi}}\right)
$$

Subject to the budget constraint

$$
\vec{K}_{t+1}=\left(1-\delta\left(u_{t}\right)\right) \vec{K}_{t}+\vec{W}_{t} L_{t}+u_{t} R_{t} \vec{K}_{t}+\vec{\Pi}_{t}-\vec{C}_{t}-\frac{\gamma}{2} \frac{\left(\frac{\vec{K}_{t+1}}{(1+g)}-\vec{K}_{t}\right)^{2}}{\vec{K}_{t}}
$$

There is monopolistic competition in the intermediate goods markets. The production function is:

$$
\vec{y}_{i t}=q_{i t} \theta_{t} \vec{k}_{i t}^{1-\alpha}\left((1+g)^{t} l_{i t}\right)^{\alpha}
$$

Note that $k$ denotes the flow of capital services (including the $u$ term) and $l$ is labor. $\theta_{t}$ is an aggregate productivity shock, $q_{i t}$ is firm's idiosyncratic productivity. $(1+g)$ is the Harrod-neutral trend growth. The profits are

$$
\begin{aligned}
& \vec{\pi}_{i t}=\frac{p_{i t}}{p_{t}} \vec{y}_{i t}-\vec{W}_{t} l_{i t}-R_{t} \vec{k}_{i t}-\vec{\Phi}_{i t} \\
& \vec{\Phi}_{i t}=\vec{\Phi} \times\left(1+\tau_{i t}\right)
\end{aligned}
$$

There is a fixed cost in terms of goods $(\vec{\Phi})$ indexed on aggregate productivity to keep the number of firms constant on the balanced growth path. I now remove the trend $(1+g)^{t}$. Define for the wage (and similarly for all other trending variables):

$$
W_{t}=\frac{\vec{W}_{t}}{(1+g)^{t}}
$$

So the marginal cost of firm $i$ is

$$
\begin{aligned}
c_{i t} & =\frac{\chi_{t}}{q_{i t}} \\
\chi_{t} & \equiv \frac{1}{\theta_{t}}\left(\frac{R_{t}}{1-\alpha}\right)^{1-\alpha}\left(\frac{W_{t}}{\alpha}\right)^{\alpha}
\end{aligned}
$$

Let's compute first the monopoly solution

$$
\max \left(\frac{p_{i t}}{p_{t}}-c_{i t}\right) y_{i t}
$$


This monopolist chooses a markup $\mu=\frac{\sigma}{\sigma-1}$ and prices at $\frac{p_{i t}^{m}}{p_{t}}=\frac{\mu \chi_{t}}{q_{i t}}$. The quantities produced and hired are:

$$
\begin{aligned}
y_{i t}^{m} & =\frac{Y_{t}}{N}\left(\frac{1}{\mu c_{i t}}\right)^{\sigma}=\frac{Y_{t}}{N\left(\mu \chi_{t}\right)^{\sigma}} q_{i t}^{\sigma} \\
l_{i t}^{m} & =\frac{\alpha}{1-\alpha} \frac{R_{t}}{W_{t}} k_{i t}^{m} \\
k_{i t}^{m} & =\frac{y_{i t}^{m}}{\theta_{t} q_{i t}}\left(\frac{1-\alpha}{\alpha} \frac{W_{t}}{R_{t}}\right)^{\alpha}
\end{aligned}
$$

The profits of the firm are:

$$
\begin{aligned}
\pi_{i t}^{m} & =A_{t} q_{i t}^{\sigma-1}-\Phi \\
A_{t} & \equiv\left(\mu \chi_{t}\right)^{1-\sigma} \frac{Y_{t}}{\sigma N}
\end{aligned}
$$

But the manager proposes a bigger firm

$$
\begin{aligned}
\frac{l_{i t}}{l_{i t}^{m}} & =\frac{k_{i t}}{k_{i t}^{m}}=1+\eta_{i t} \\
\frac{p_{i t}}{p_{i t}^{m}} & =\left(1+\eta_{i t}\right)^{-\frac{1}{\sigma}}
\end{aligned}
$$

The profits become:

$$
\begin{aligned}
\pi_{i t} & =A_{t} q_{i t}^{\sigma-1} \kappa\left(\eta_{i t}\right)-\Phi-\tau_{i t} \Phi \\
\kappa\left(\eta_{i t}\right) & \equiv\left(1+\eta_{i t}\right) \times \frac{\mu\left(1+\eta_{i t}\right)^{-\frac{1}{\sigma}}-1}{\mu-1}
\end{aligned}
$$

The aggregate price level condition is:

$$
\int_{0}^{1}\left(q_{i t}\right)^{\sigma-1}\left(1+\eta_{i t}\right)^{\frac{\sigma-1}{\sigma}}=\left(\mu \chi_{t}\right)^{\sigma-1}
$$

And the aggregate demands for capital and labor are:

$$
\begin{aligned}
\frac{L_{t}^{d}}{K_{t}^{d}} & =\frac{\alpha}{1-\alpha} \frac{R_{t}}{W_{t}} \\
K_{t}^{d} & =\left(\frac{1-\alpha}{\alpha} \frac{W_{t}}{R_{t}}\right)^{\alpha} \frac{\Psi_{t}}{\left(\mu \chi_{t}\right)^{\sigma}} \frac{Y_{t}}{\theta_{t}} \\
\Psi_{t} & \equiv \int_{0}^{1}\left(1+\eta_{i t}\right) q_{i t}^{\sigma-1}
\end{aligned}
$$

The equilibrium in the capital market gives:

$$
K_{t}^{d}=u_{t} K_{t}
$$




\section{C.1 Complete Model}

Firms with good governance $\left(\underline{q}_{i}>Q_{t}\right)$ choose to enforce shareholders rights. Other firms Governance decisions lead to:

$$
\begin{aligned}
\Psi_{t} & \equiv \int_{0}^{1}\left(1+\eta_{i t}\right) q_{i t}^{\sigma-1}=\int_{0}^{Q_{t}}\left(1+\eta^{*}\right) f(q) d q+\int_{Q_{t}}^{1} q^{\sigma-1} f(q) d q \\
\Psi_{t} & =\left(1+\eta^{*}\right) \times F\left(Q_{t}\right)+G\left(Q_{t}\right) \\
F\left(Q_{t}\right) & =\int_{0}^{Q_{t}} f(q) d q \\
G\left(Q_{t}\right) & =\int_{Q_{t}}^{1} q^{\sigma-1} f(q) d q
\end{aligned}
$$

And for the marginal cost I get:

$$
\begin{aligned}
& \chi_{t}=\frac{1}{\mu}\left[\int_{0}^{1}\left(1+\eta_{i t}\right)^{\frac{\sigma-1}{\sigma}} q_{i t}^{\sigma-1}\right]^{\frac{1}{\sigma-1}} \\
& \chi_{t}=\frac{1}{\mu}\left[\left(1+\eta^{*}\right)^{\frac{1}{\mu}} \times F\left(Q_{t}\right)+G\left(Q_{t}\right)\right]^{\frac{1}{\sigma-1}}
\end{aligned}
$$

So the complete model is described by the following equations:

- Labor supply and labor demand:

$$
\begin{aligned}
L_{t} & =\left(\frac{Z_{t} W_{t}}{C_{t}}\right)^{\phi} \\
\frac{L_{t}}{u_{t} K_{t}} & =\frac{\alpha}{1-\alpha} \frac{R_{t}}{W_{t}}
\end{aligned}
$$

- Euler equation

$$
\frac{1}{C_{t}}\left(1+\gamma \frac{K_{t+1}-K_{t}}{K_{t}}\right)=\frac{\beta}{1+g} E_{t}\left[\frac{1}{C_{t+1}}\left(1+u_{t+1} R_{t+1}-\delta_{t+1}+\gamma \frac{K_{t+2}-K_{t+1}}{K_{t+1}}\right)\right]
$$

- Utilization

$$
\delta^{\prime}\left(u_{t}\right)=R_{t}
$$

- Capital accumulation

$$
(1+g) K_{t+1}=Y_{t}+\left(1-\delta\left(u_{t}\right)\right) K_{t}-C_{t}-N \Phi-N \Phi \tau^{*} F\left(Q_{t}\right)-\frac{\gamma}{2} \frac{\left(K_{t+1}-K_{t}\right)^{2}}{K_{t}}
$$

- Capital demand

$$
u_{t} K_{t}=\left(\frac{1-\alpha}{\alpha} \frac{W_{t}}{R_{t}}\right)^{\alpha} \frac{\Psi_{t}}{\left(\mu \chi_{t}\right)^{\sigma}} \frac{Y_{t}}{\theta_{t}}
$$

- Marginal cost

$$
\chi_{t} \equiv \frac{1}{\theta_{t}}\left(\frac{R_{t}}{1-\alpha}\right)^{1-\alpha}\left(\frac{W_{t}}{\alpha}\right)^{\alpha}
$$


- The cutoff is such that

$$
\begin{aligned}
\underline{q}_{t}^{\sigma-1} A_{t} & =A_{t} \kappa^{*}-\tau^{*} \Phi \\
A_{t} & \equiv\left(\mu \chi_{t}\right)^{1-\sigma} \frac{Y_{t}}{\sigma N}
\end{aligned}
$$

- Finally the free entry condition says that (unconditional) expected profits have to be 0 . This assumes for simplicity that governance is randomly drawn after entry.

$$
E\left[\pi_{i t}\right]=0
$$




\begin{tabular}{|c|c|c|c|c|c|c|c|c|c|c|c|c|}
\hline $\begin{array}{l}\text { Table 1. Estimat } \\
\text { regression of the grow } \\
\text { coefficients are reporte } \\
\text { meaningful, all aggreg } \\
1<\mathrm{G}<=7 \text { (Good Gover }\end{array}$ & $\begin{array}{l}\mathbf{n} \text { of } \mathbf{F} \\
\text { rate of c } \\
\text { Same re } \\
\text { e variabl } \\
\text { nce). Re }\end{array}$ & $\begin{array}{l}\text { Sens } \\
\text { al expen } \\
\text { ssions ar } \\
\text { re rescal } \\
\text { ssion coe }\end{array}$ & $\begin{array}{l}\text { ity to } \\
\text { res on th } \\
\text { in for sal } \\
\text { o that av } \\
\text { ients are }\end{array}$ & $\begin{array}{l}\text { oregat } \\
\text { owth rat } \\
\text { on GDP) } \\
\text { ge beta is } \\
\text { old, t-sta }\end{array}$ & $\begin{array}{l}\text { hocks. } \\
\text { aggrega } \\
\text { for emp } \\
\text { the san } \\
\text { ics in ita }\end{array}$ & $\begin{array}{l}\text { asitivity } \\
\text { ivestmen } \\
\text { ment (on } \\
\text { See apr } \\
\text { Sample }\end{array}$ & $\begin{array}{l}\text { apital ex } \\
\text { teracted } \\
\text { gregate e } \\
\text { lix for de } \\
\text { iod: } 198\end{array}$ & $\begin{array}{l}\text { ditures ( } 1 \\
\text { h govern } \\
\text { oyment) } \\
\text { s on data } \\
01 \text {. Ann }\end{array}$ & $\begin{array}{l}\text { essions } 1 \\
\text { e and otl } \\
\text { make c } \\
\text { ne omitte } \\
\text { Data. }\end{array}$ & $\begin{array}{l}\text { 4) is the } \\
\text { control v } \\
\text { arison ac } \\
\text { ategory } f\end{array}$ & $\begin{array}{l}\text { fficient fr } \\
\text { bles. Onl } \\
\text { s regressi } \\
\text { jovernan }\end{array}$ & $\begin{array}{l}\text { the } \\
\text { teraction } \\
\text { s }\end{array}$ \\
\hline & 1 & & & 4 & 5 & 6 & 7 & 8 & 9 & & 11 & 12 \\
\hline Dependent Variable & & Inve & nent & & & & & & & Emp & ment & \\
\hline & Governa & Index & 1 as $\operatorname{Lin}$ & Regress & from 5 & 4), inter & ed with & wth Ra & f Aggre & e Variab & & \\
\hline G & $\begin{array}{l}\mathbf{0 . 1 0 9} \\
2.880\end{array}$ & $\begin{array}{l}\mathbf{0 . 0 8 0} \\
1.960\end{array}$ & & & $\begin{array}{l}\mathbf{0 . 0 6 1} \\
2.520\end{array}$ & $\begin{array}{l}\mathbf{0 . 0 6 4} \\
2.450\end{array}$ & & & $\begin{array}{l}\mathbf{0 . 0 9 5} \\
2.720\end{array}$ & $\begin{array}{l}\mathbf{0 . 1 1 2} \\
2.990\end{array}$ & & \\
\hline & Govern & Index & d to cre & Govern & e Categ & s, intera & d with C & wth Rate & Aggreg & Variabl & & \\
\hline $8<=G<=12$ & & & 0.446 & 0.382 & & & 0.213 & 0.226 & & & 0.384 & 0.498 \\
\hline & & & 1.840 & 1.510 & & & 1.380 & 1.410 & & & 1.730 & 2.160 \\
\hline $12<-C$ & & & 0.942 & 0.708 & & & 0.492 & 0.462 & & & 0.812 & 0.916 \\
\hline $15<=U$ & & & 2.990 & 2.110 & & & 2.430 & 2.150 & & & 2.800 & 2.980 \\
\hline & & & ther $\mathrm{Cc}$ & ols inter & d with & wth Ra & Aggre & Variab & & & & \\
\hline Firm Age Dummies & no & yes & no & yes & no & yes & no & yes & no & yes & no & yes \\
\hline Industry Dummies & no & yes & no & yes & no & yes & no & yes & no & yes & no & yes \\
\hline Firm Fixed Effects & yes & yes & yes & yes & yes & yes & yes & yes & yes & yes & yes & yes \\
\hline $\mathrm{R}^{2} \%$ & 14.28 & 14.54 & 14.28 & 14.54 & 22.94 & 23.16 & 22.93 & 23.15 & 25.74 & 25.90 & 25.74 & 25.90 \\
\hline N. Firms & 617 & 617 & 617 & 617 & 626 & 626 & 626 & 626 & 622 & 622 & 622 & 622 \\
\hline N. Observations & 7829 & 7829 & 7829 & 7829 & 8025 & 8025 & 8025 & 8025 & 7790 & 7790 & 7790 & 7790 \\
\hline
\end{tabular}




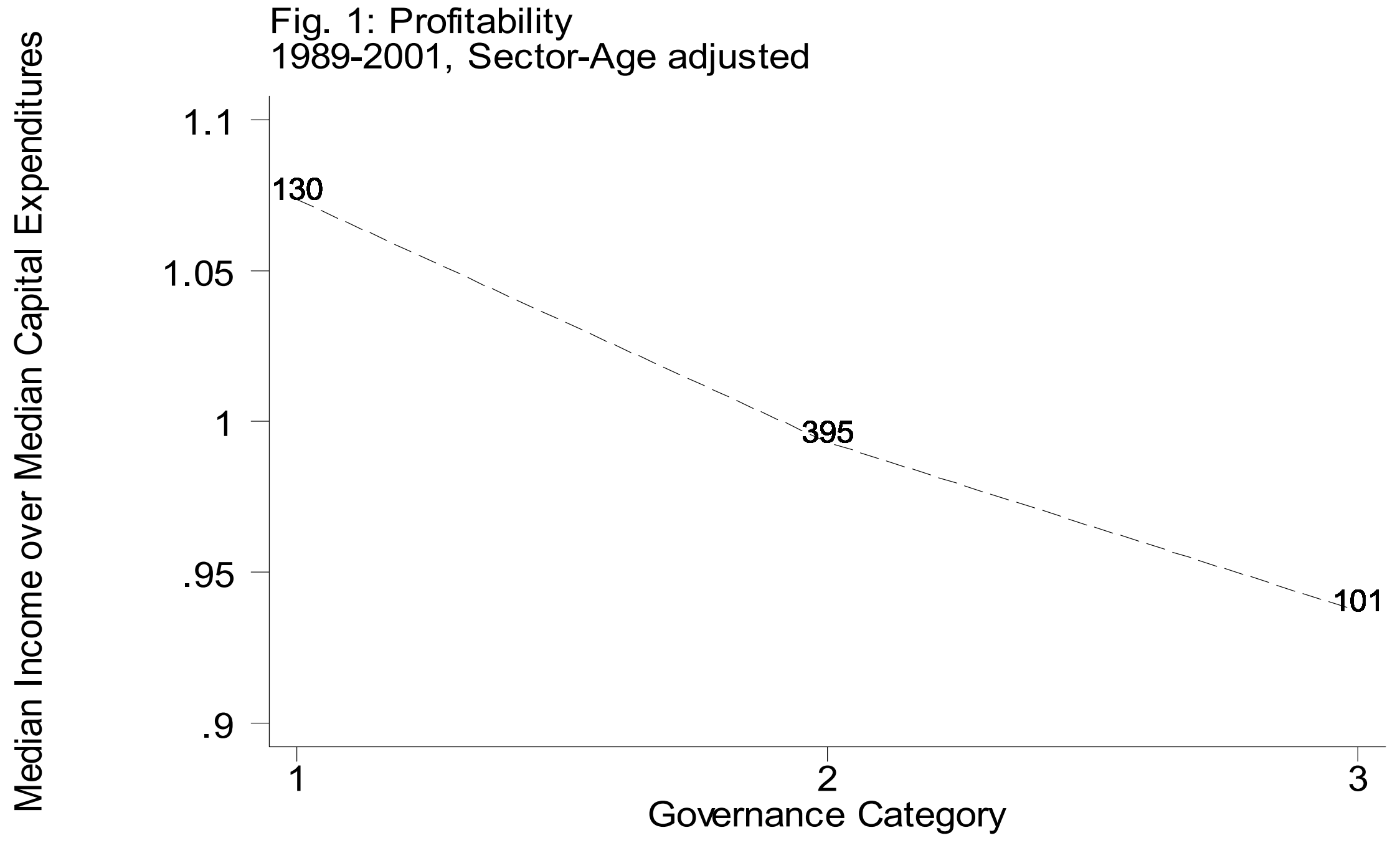

Notes: Income over capital expenditures is rescaled to have mean of 1 . Sample size (number of firms) for each governance category is indicated on the graph. Source: Compustat annual files for accounting data and Gompers, Ishii and Metrick (2003) for governance data. 
Fig. 2a: Sensitivity of Investment to Aggregate Shocks 1989-2001, Sector-Age adjusted

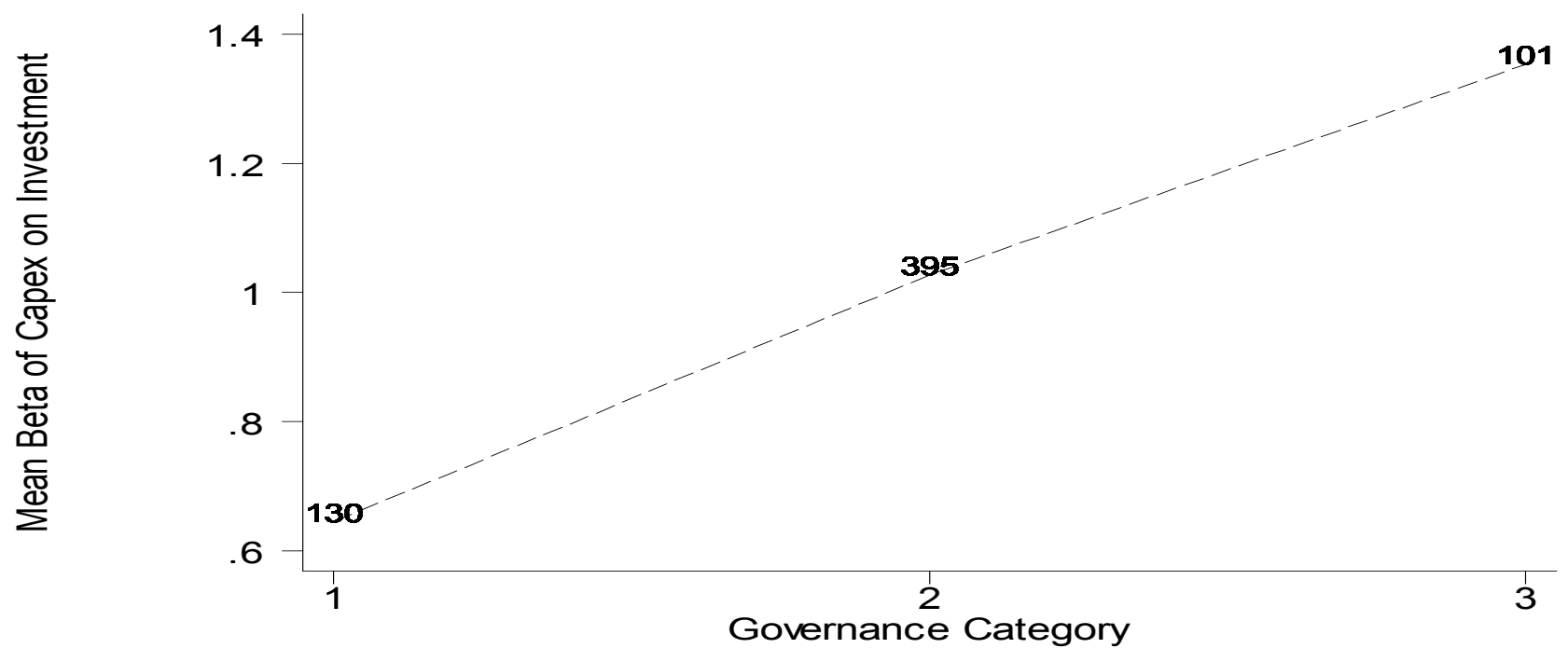

Fig. 2b: Sensitivity of Sales to Aggregate Shocks 1989-2001, Sector-Age adjusted

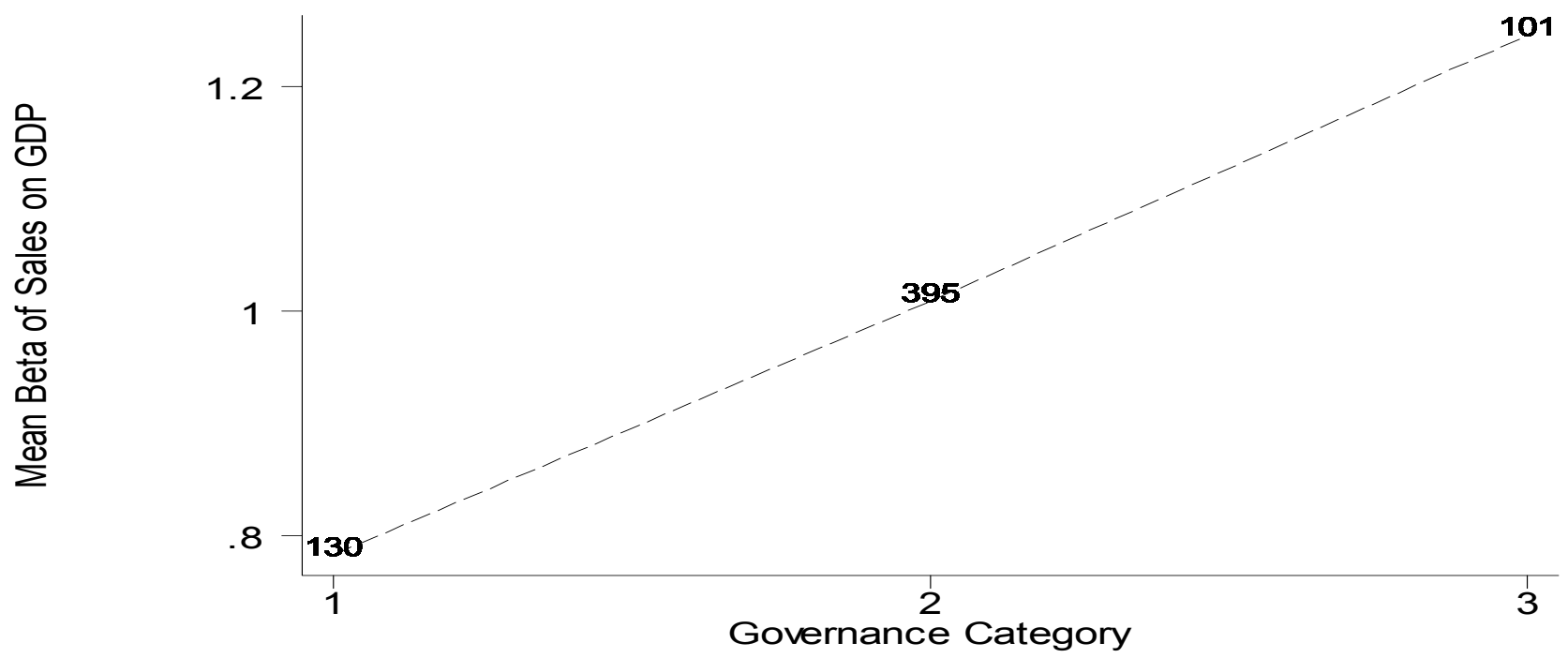

Notes: Regression beta of capital expenditures growth on aggregate investment growth (2a) and sales growth on GDP growth (2b). Betas are rescaled to have mean of 1 and are adjusted for sector and age groups. Regression results are reported in Table 1. Sample size (number of firms) for each governance category is indicated on the graph. Source: Compustat annual files for accounting data and Gompers, Ishii and Metrick (2003) for governance data. 
FIG. 3a: CALIBRATED PROFIT MARGINS and GOVERNANCE

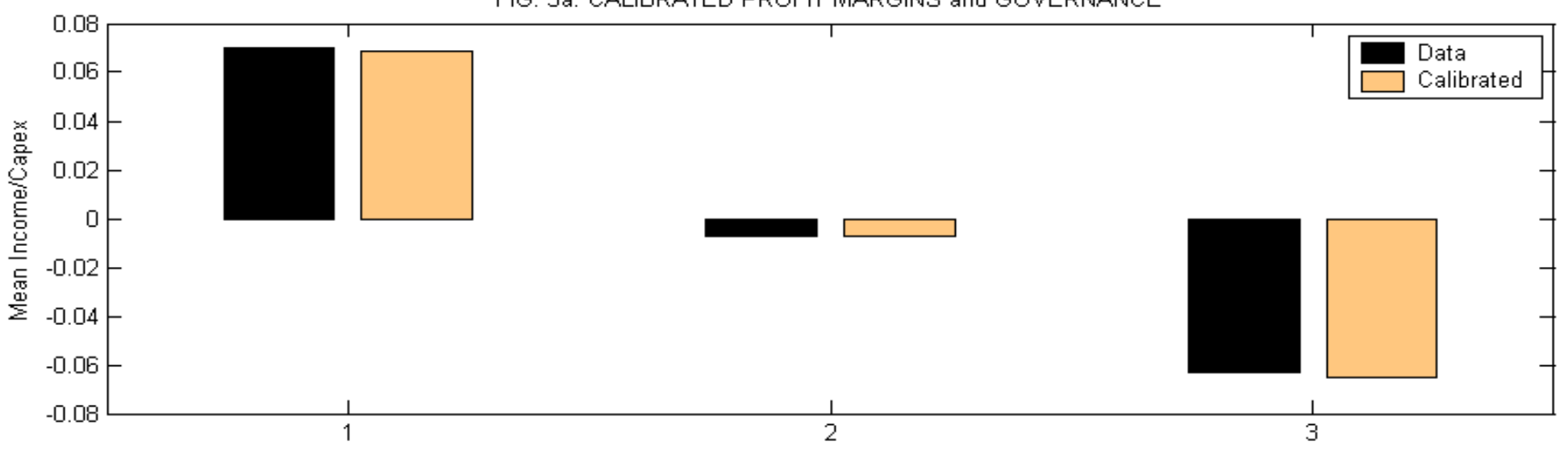

FIG. 3b: CALIBRATED BETAS and GOVERNANCE

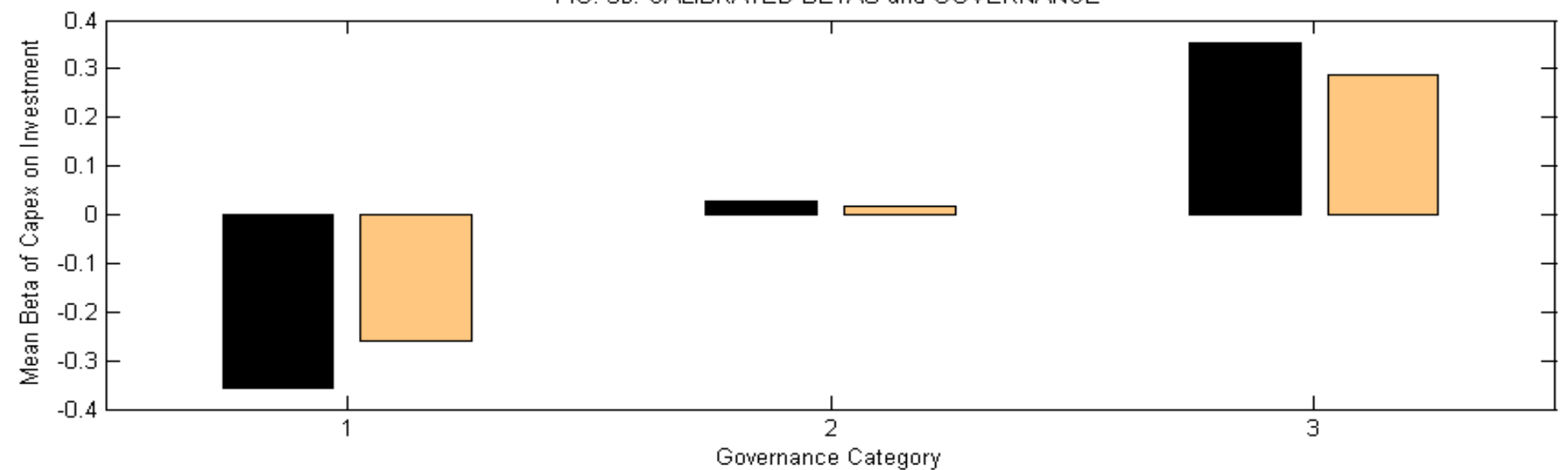

Notes: The distribution of firms in 3 groups corresponds to the empirical distribution: 130 have good governance (category 1 , bottom $25 \%$ ), 395 have normal governance (category 2, middle 50\%), and 101 have bad governance (category 3 , top 25\%). The model matches the number of firms (exactly), the average profit margin and the average beta in each group (approximately). 
FIG. 4: RESPONSE TO POSITIVE LABOR SHOCK, Z

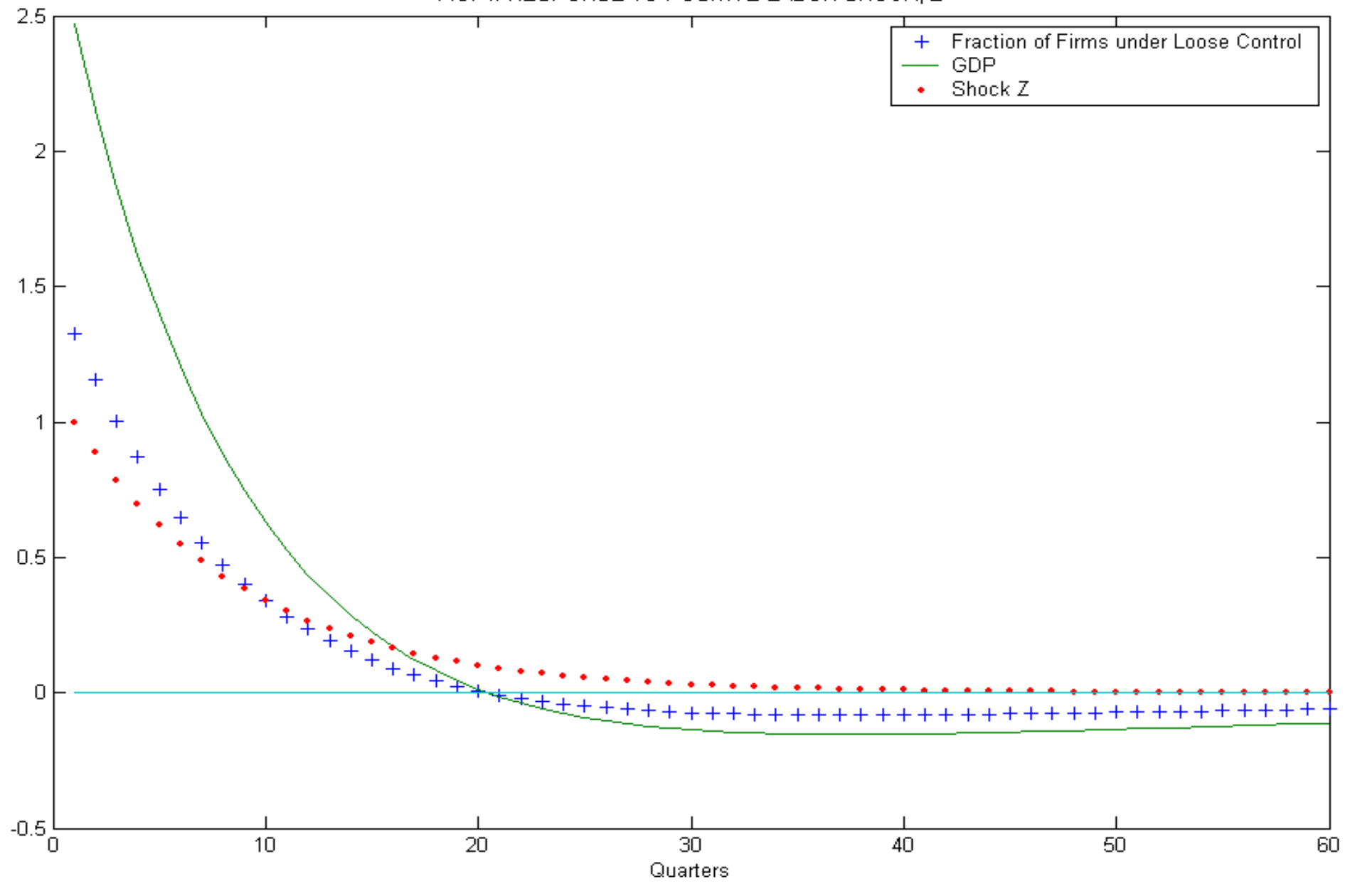


FIG. 5: GDP RESPONSE TO LABOR SHOCK Z

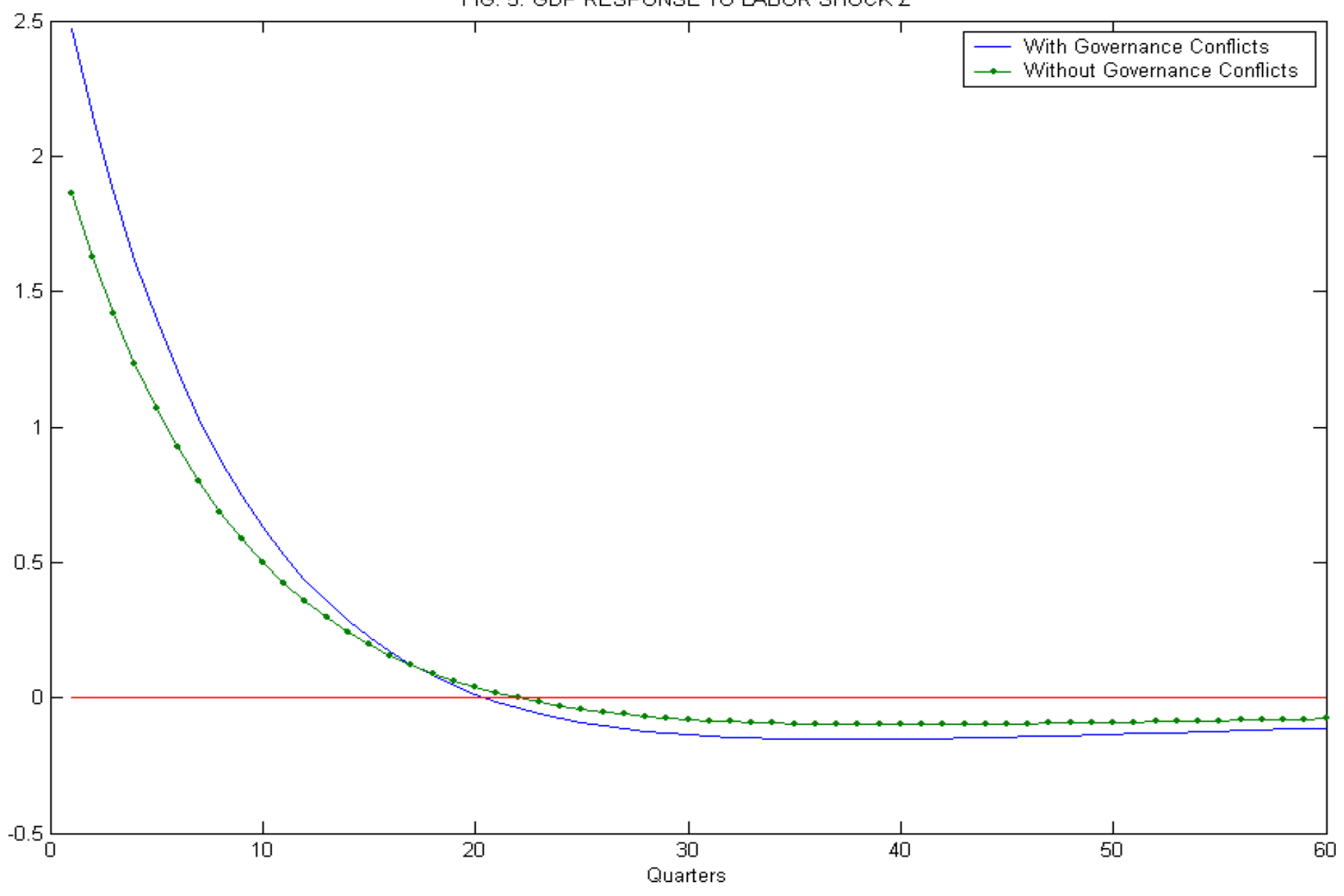



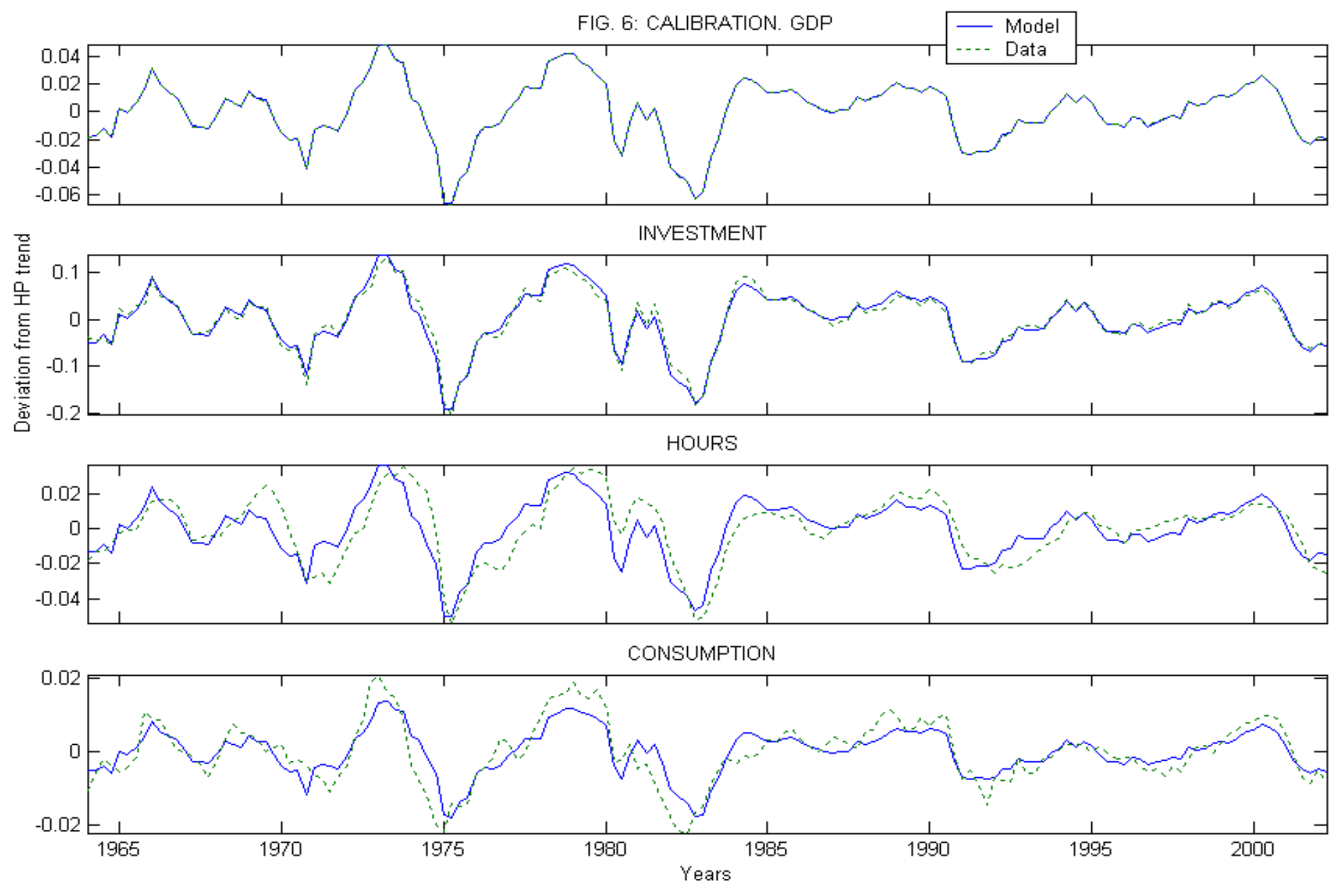
FIG. 7: FRACTION OF FIRMS UNDER LOOSE CONTROL

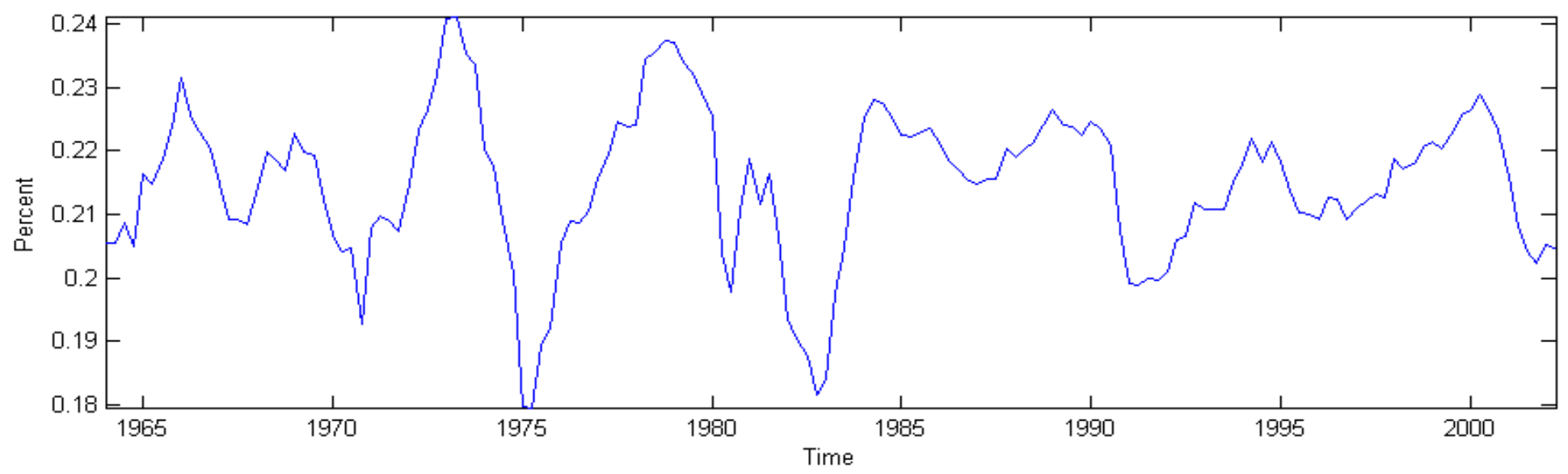

FIG. 8: IMPLIED AND ACTUAL SOLOW RESIDUALS

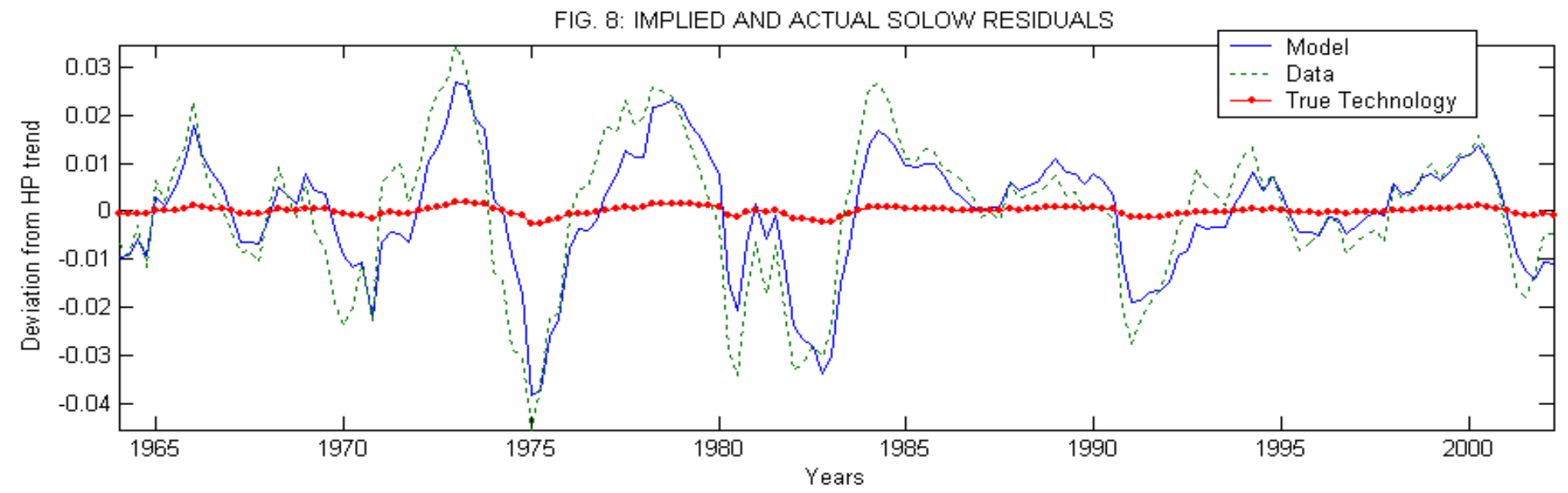

